\title{
MAIORIDADE PENAL NO BRASIL E NA ESPANHA: UM ESTUDO COMPARATIVO
}

\section{Elaine Marinho Faria e Maria Amélia da Silva Castro ${ }^{1}$}

Resumo: O trabalho traça um panorama geral da legislação referente à maioridade penal no Brasil e na Espanha. O tema é apresentado sob uma perspectiva histórica e mostra a evolução no tratamento da infância e da adolescência nos dois países. No período anterior ao século XX, tanto no Brasil como na Espanha, as crianças com menos de nove anos eram consideradas inimputáveis. Para os maiores de nove anos, o critério utilizado para a definição da inimputabilidade era a capacidade de discernimento. Esse era um critério bastante subjetivo, e a verificação da aptidão do jovem para distinguir o bem do mal era uma das decisões mais difíceis para os juízes. No início do século XX, começaram a surgir leis específicas sobre menores com o objetivo de resguardar e proteger crianças e jovens. Atualmente, a legislação sobre menores nos dois países segue os princípios previstos pelas normas internacionais. A maioridade penal está fixada em dezoito anos. A lei estabelece uma série de medidas aplicáveis aos menores sob a perspectiva socioeducativa, respeitando sempre a peculiar condição do adolescente como um ser em desenvolvimento. O objetivo do trabalho é comparar a legislação de menores e as medidas socioeducativas adotadas em ambos os países com o intuito de trazer subsídios para a busca de soluções da problemática do aumento da criminalidade infanto-juvenil em nosso país.

Palavras-chave: maioridade penal; estudo comparado

Abstract: This work presents a general view of the legislation regarding criminal majority in Brazil and Spain. The theme is presented in a historical perspective and shows the evolution in the treatment of childhood and adolescence in both countries. In the period before to the twentieth century both Brazil and Spain, children under nine years old were considered incompetent. For those over the age of nine years old the criterion used to define the incapacity

\footnotetext{
${ }^{1}$ Elaine Marinho Faria é graduada em Biblioteconomia e tem cursos de Especialização em Terceiro Setor/ Política/Direitos Humanos, tendo sido conselheira distrital de direitos humanos de 2005 à 2007 (elaine.faria@camara.gov.br). Maria Amélia da Silva Castro é graduada em Administração de Empresas, com Especialização em Políticas Públicas (maria.castro@camara.gov.br).
} 
was the ability of discernment. This was a very subjective criterion and verification of the ability of young to distinguish between good and evil was one of the most difficult decisions for judges. At the beginning of the 20th century began to appear specific laws about minors with the objective to safeguard and protect children and youth. The justice model had the tutelary and health care character, measures implemented should have therapeutic orientation, protective and reformer. Currently, the law about minors in the two countries follows the principles proposed by international rules. The age of criminal responsibility is set at eighteen years old. The law establishes a series of measures applicable to minors under the social-educational perspective, always respecting the peculiar condition of a growing human. This objective is to compare the legislation of minors and social-educational measures adopted in both of countries in order to provide elements for the search for solutions to the problem of increasing criminality juvenile in our country.

Key Words: criminal majority; comparative study

\section{Introdução}

O tema da maioridade penal tem sido uma preocupação mundial. As discussões se dividem entre o aumento da criminalidade infanto-juvenil e a possibilidade de se retirar do convívio da sociedade uma massa de jovens ainda na tenra idade. Um dos pontos mais polêmicos diz respeito à definição de um limite para a imputabilidade penal, pois as idades variam de oito a dezoito anos, dependendo das características de cada país. O tema é complexo, afinal de contas com que idade um ser humano normal está apto a compreender a ilicitude de seus atos?

Uma parte da sociedade defende a redução da maioridade penal para dezesseis anos, por entender que o jovem nessa faixa etária, nos dias atuais, tem capacidade plena para distinguir o certo do errado. Já outra parte luta pela manutenção da idade de dezoito anos e argumenta que a redução da maioridade, além de não resolver os problemas ligados ao aumento da criminalidade, poderia agravá-los, uma vez que estimularia o crime organizado a recrutar para suas fileiras jovens de faixa etária cada vez mais baixa.

O debate continua acirrado e deverá ganhar contornos mais definidos com o início da $54^{a}$ Legislatura. Nesse contexto, é importante conhecer a legislação de outros Países cuja experiência possa levar a um maior aprofundamento do debate e, em consequência, trazer subsídios para que o Brasil encontre o melhor caminho dentro de sua realidade política, social e democrática. 
Assim, o texto a seguir tem como proposta apresentar a evolução da legislação espanhola sobre menores e compará-la à legislação brasileira. A escolha da Espanha não se deu por acaso, pois a história de proteção aos menores nos dois países é bastante parecida. Após a promulgação de suas constituições democráticas - Espanha, em 1978 e Brasil, em 1988 -, ambos os países romperam com o modelo de caráter protecionista e tutelar até então dispensados aos menores de idade.

No Brasil, a mudança ocorreu em 1990, com a criação do Estatuto da Criança e do Adolescente (ECA), ao passo que, na Espanha, a Lei de Menores foi promulgada em 1992 (Lei Orgánica 4/1992). A partir dessas leis, os menores de idade passam a contar com todas as garantias derivadas do ordenamento constitucional, porém o Estatuto brasileiro já definia a maioridade penal aos dezoito anos, enquanto a Lei espanhola manteve a idade de dezesseis anos até 1995.

\section{Proteção do Menor no Brasil - histórico}

Conforme Soares (2008), quando D. João VI desembarcou no Brasil com sua corte, em 1808, as Ordenações Filipinas estavam em vigor, isto quer dizer que a imputabilidade penal iniciava-se aos sete anos, eximindo o menor da pena de morte. Os jovens eram severamente punidos, sem muita diferenciação quanto aos adultos.

Aos jovens entre dezessete e vinte anos, havia uma diminuição da pena em um terço em relação aos adultos, de acordo como o juízo do magistrado, adotando-se, para tal caso, os três critérios objetivos e um subjetivo. Os critérios objetivos eram: a) modo como o delito foi praticado; b) suas circunstâncias; c) a pessoa do menor. Já o critério subjetivo estava relacionado à malícia da ação. Já aos jovens entre sete e dezessete anos, o soberano concedeu o "privilégio" de não serem condenados a pena de morte, subsistindo todas as outras políticas penais, como custódia no mesmo estabelecimento prisional, sem qualquer diferenciação na execução da pena. Percebe-se que a inimputabilidade penal plena só ocorria para os menores de sete anos de idade. Apesar do total abandono à criança na época imperial, segundo Sousa (2001, p. 55), foram adotadas no Brasil, por influência da ideologia cristã, medidas políticas educacionais para a infância, como a Casa de Roda ${ }^{2}$, que foi fundada em 1726 na Bahia; a Casa dos Enjeitados ${ }^{3}$ no Rio de Janeiro em 1738, e a Casa dos Expostos ${ }^{4}$, cujas finalidades eram o abrigo de crianças e adolescentes órfãos ou abandonados.

\footnotetext{
${ }^{2}$ Essas casas possuíam uma espécie de roleta, onde crianças nascidas em famílias pobres ou mesmo havidas fora do casamento eram deixadas sem que se identificasse quem as abandonava, conforme explica (Rizzini, I. e Rizzini, 2004).

${ }^{3}$ Em 1738, por iniciativa pessoal do comerciante português Romão de Mattos Duarte, foi fundada a Casa da Roda, depois chamada de Casa dos Expostos, atualmente Educandário Romão de Mattos Duarte, em homenagem ao seu fundador.

${ }^{4}$ A instalação da Casa dos Expostos, no Recife, data do final do século XVIII. 
Em 1830, foi criado o Código Penal do Império, inspirado no Código Penal Francês de 1810, que adotou o sistema de discernimento, determinando a maioridade penal absoluta a partir dos quartorze anos, mas os menores abaixo desta idade poderiam ser considerados penalmente responsáveis se agissem com discernimento. O discernimento adotado nesse Código permitia que até mesmo uma criança de oito anos e um adolescente de quinze pudessem ser condenados à prisão perpétua.

O Código Penal Republicano de $1890^{5}$ determinava a inimputabilidade absoluta até os nove anos completos. Os maiores de nove anos e os menores de quatorze estariam sujeitos ao sistema do discernimento. O critério era bastante subjetivo, e a verificação da aptidão para distinguir o bem do mal - o reconhecimento do menor possuir relativa lucidez - era uma das decisões mais difíceis para os juízes.

A primeira legislação brasileira a tratar do tema entrou em vigor em 1921, por intermédio da Lei Orçamentária $n^{\circ} 4.242^{6}$, que trazia especificações de um Código de Menores, no qual era definido abandono, suspensão, perda do pátrio poder, além de determinar a utilização de procedimentos especiais.

Apesar dessa legislação só ter sido aprovada em 1921, outros projetos estiveram presentes no cenário legislativo, como o Lopes Trovão (1902) e Alcindo Guanabara (1906 e 1917), este último tratando da inimputabilidade dos menores entre doze e dezessete anos (Santos, 2008).

Ainda, conforme Santos (2008), o Direito Menorista ganhou vulto, passando a ser regulado pelo Código de Menores de 12 de outubro de 1927, que modificou a Lei 5.228, de 1967, que foi alterada pela Lei 5.5.39, de 1968, ambas já na vigência do Código Penal de 1940, que limitou a menoridade penal aos dezoito anos.

Em 1926, o Congresso Nacional concedeu ao Poder Executivo uma autorização para consolidar as leis sobre menores, sob a denominação de Código. No dia 12 de outubro de 1927, o Decreto 17.943-A consolidou as leis relativas a menores, instituindo o Código de Menores, o primeiro da América Latina. O Código veio a alterar e substituir concepções obsoletas como: discernimento, culpabilidade, penalidade, responsabilidade, pátrio poder. Foi abandonada a postura de reprimir e punir, passando a ser priorizada a postura de regenerar e educar.

Segundo Pereira (2008), o Código de Menores de 1927 tinha as seguintes características: a) concepção política social - instrumento de proteção e vigilância da infância e adolescência, vítima da omissão e transgressão da família, em seus direitos básicos. O menor abandonado ou delinquente, objeto de vigilância da autoridade pública (juiz); b) instituição do

\footnotetext{
${ }^{5}$ O código foi promulgado pelo Decreto $\mathrm{n}^{\circ} 22.213$, de 14 de dezembro do mesmo ano, mas só entrou em vigor seis anos depois.
} 
Conselho de Assistência e Proteção aos Menores, como associação de utilidade pública, com personalidade jurídica; c) a função dos Conselheiros, nomeados pelo Governo, era auxiliar o Juízo de Menores, sendo os Conselheiros denominados "Delegados da Assistência e Proteção aos Menores"; d) elevação da idade da irresponsabilidade penal do menor para quatorze anos; e) criação de um esboço de Polícia Especial de Menores dentro dos comissários de vigilância. Foi o Código que consolidou a legislação sobre crianças e consagrou-lhe um sistema de atendimento, estabelecendo as regras do desvio social. Pela primeira vez no Brasil, crianças menores de sete anos recebiam o nome de expostas; os menores de dezoito anos, de abandonados; os meninos de rua, de vadios; as que pediam esmola, de mendigos, e as frequentadoras de prostíbulos, de libertinas.

O Código previa que o descumprimento de qualquer obrigação estipulada aos pais pelo Código Civil, bem como a conduta antissocial da criança, eram motivos para que fosse transferida a tutela dos pais para o Juiz (Silva 2008).

Segundo Simões (2009), o Código Penal, promulgado pelo Decreto-Lei ${ }^{\circ} 2848$, de 1940, adotou o sistema biológico, no qual se presume que os menores de dezoito anos são inimputáveis - isto é, incapazes de entender o caráter ilícito de certos atos e de controlar sua própria vontade - classificando-os de possuir desenvolvimento mental incompleto ou imaturidade natural.

Para Silva (2005), o Código Penal de 1940 instituiu aos maiores de dezesseis anos a possibilidade da liberdade vigiada, pela qual a família ou os tutores deveriam se responsabilizar pelo processo de regeneração do menor, com as obrigações de reparação dos danos causados e de apresentação do menor em juízo. Estendeu a autoridade do Juiz sobre os jovens entre dezoito e vinte e um anos.

A substituição do Código Penal foi tentada pelo Decreto-Lei n ${ }^{\circ}$ 1004, de 21 de outubro de 1969, mas as críticas foram grandes. Em 1969, seu artigo 33 estabeleceu o retorno do critério biopsicológico, possibilitando a aplicação de pena ao maior de dezesseis anos e menor de dezoito anos, desde que este entendesse o caráter ilícito do ato ou tivesse possibilidade de se portar de acordo com o estabelecido. Ele foi modificado substancialmente pela Lei $\mathrm{n}^{\circ} 6.061$, de 31 de dezembro de 1973, posteriormente revogada pela Lei 6.578, de 11 de outubro de 1978.

Com o intuito de romper com a doutrina do Direito Penal do Menor, conforme Segalin (2006), foi criado o Código de Menores de 1979, que adotou a Doutrina Jurídica do Menor em Situação Irregular. A infância ficava dividida em duas categorias: as crianças e adolescentes considerada infância normal, sob os cuidados da família - e a população infanto-juvenil de rua. Nesta última categoria estavam incluídos os órfãos, os carentes e os infratores (Segalin;

\footnotetext{
${ }^{6}$ A Lei Orçamentária 4242 de 1921 criou o Serviço de Assistência e Proteção à Infância Abandonada e Delinquente. Isso gerou a fundação de duas instituições para menores, na ampliação da Escola 15 de novembro e na nomeação de 
Trzcinzski, 2006). O Código tinha como objetivo oferecer assistência, proteção e vigilância aos menores de até dezoito anos.

Apesar de o Código não ter se preocupado em diferenciar infratores, abandonados ou órfãos, sua criação contribuiu para a reconstrução de um Estado mais organizado, uma vez que, ao proteger o menor em situação irregular, estaria também colaborando com a família. $\mathrm{O}$ foco era legitimar a atuação estatal, exercida pelo Poder Judiciário, o que beneficiaria a institucionalização e a adoção. No caso de crianças em situação irregular, o dever do Estado era dar assistência e, em consequência, garantir o controle social.

Esse código vigorou até 1990, quando da promulgação da Lei 8.069, de 14 de outubro de $1990^{7}$, que instituiu o Estatuto da Criança e do Adolescente- ECA.

\section{Estatuto da Criança e do Adolescente - ECA}

O Estatuto da Criança e do Adolescente - ECA - foi criado para substituir o Código de Menores. O ECA foi responsável por uma redefinição da forma de atendimento a ser dado a crianças e adolescentes no País, nas mais diversas esferas de seus interesses, por meio de um sistema de preceitos que procura implementar a teoria da proteção integral. Representa um pacto político-social que se organiza em três eixos: universal - para todas as crianças e adolescentes; de políticas públicas (art. $4^{\circ}$ ); protetivo - alcança crianças e adolescentes vitimizados (art. 101), e socioeducativo - aos adolescentes vitimizados (art. 112). Veio consolidar os anseios de benefícios à população infanto-juvenil no Brasil, sendo fundamental para garantir a condição de sujeitos de direitos à criança e ao adolescente.

A implantação do ECA proporcionou o caráter protecionista integral aos adolescentes. Dentre os diversos avanços estabelecidos pelo ECA, ressalta-se a criação dos Conselhos de Direitos e Tutelares, deflagração da participação do Poder Público e da sociedade organizada na elaboração de políticas sociais, garantindo e efetivando plenamente o exercício da cidadania a todas as crianças e adolescentes.

O ECA considera criança a pessoa até doze anos de idade incompletos, e adolescente, aquela entre doze e dezoito anos de idade. A Constituição Federal de 1988, em seu artigo 228, deixa claro que são penalmente inimputáveis os menores de dezoito anos sujeitos às normas da legislação especial.

um juiz de direito privado de menores. Eram utilizadas para recolhimento provisório de menores de ambos os sexos e uma casa de preservação para menores do sexo feminino.

${ }^{7}$ Lei 8069 de 13 de julho de 1990 - regulamenta os direitos das crianças e dos adolescentes inspirado pelas diretrizes fornecidas pela Constituição Federal de 1988, internalizando uma série de normativas internacionais. O Estatuto se divide em 2 livros: o primeiro trata da proteção dos direitos fundamentais a pessoa em desenvolvimento, e o segundo trata dos órgãos e procedimentos protetivos. Encontram-se os procedimentos de adoção (Livro I, capítulo V), a aplicação de medidas sócio-educativas (Livro II, capítulo II), do Conselho Tutelar (Livro II, capítulo V), e também dos crimes cometidos contra crianças e adolescentes. 
Na prática, quando o direito à vida está em jogo, até os menores de doze anos são, de certo modo, imputáveis, porque já existem no Brasil centros de internação para menores de doze anos, com comportamento de alta periculosidade. O ECA permite a internação de adolescentes infratores e proíbe a internação para crianças.

Segundo Heringer Júnior (2000), o procedimento para apuração de ato infracional praticado por adolescente passou a apresentar importantes particularidades com o ECA, principalmente com a criação do instituto da remissão ${ }^{8}$.

São medidas socioeducativas constantes do ECA, conforme Braz (2000, p. 5): a) advertência - que consiste na admoestação oral durante entrevista com juiz da Vara da Infância e da Juventude, aplicável às infrações de menor importância; b) obrigação de reparar o dano, cabível em ações que gerem lesões ao patrimônio. Objetiva despertar o senso de responsabilidade do adolescente; c) prestação de serviço à comunidade: infrator não é retirado do convívio social; d) liberdade assistida: o jovem infrator permanece sob convívio familiar, sem sofrer restrições a sua liberdade e direitos, porém suas ações são fiscalizadas e acompanhadas; e)inserção em regime de semiliberdade: esta medida deve ser acompanhada de escolarização e profissionalização, f) internação em estabelecimento educacional: não comporta prazo determinado, uma vez que a medida tem caráter regenerador do adolescente.

O ECA, em seu art. 121, $\S 3^{\circ}$, dispõe que não existirão penas perpétuas, pois a internação não poderá exceder a três anos. O princípio da brevidade e da temporalidade está contido no art. $227, \S 3^{\circ}$, da Constituição Federal. No art. 122, § $2^{\circ}$ do ECA, a privação de liberdade surge como última medida, após ser realizado todo um trabalho de convencimento e tratamento do menor infrator.

Conforme Marques (2007), O ECA estabelece a pena máxima de três anos, o que não intimida o menor infrator e, algumas vezes, faz com que ele seja pressionado a assumir a culpa de um crime que não cometeu apenas para se livrar de uma pena máxima.

\section{Proteção do Menor na Espanha}

O antecedente mais remoto da justiça de menores da Espanha data do século XIV, mais especificamente no ano de 1337, quando foi criada a figura do padre dos órfãos de Valencia, que tinha como função recolher as crianças e jovens e educá-los para o trabalho. Nas instituições da época eram recolhidos menores mendigos, órfãos ou indigentes e menores que haviam cometido algum tipo de delito.

\footnotetext{
8 O instituto da remissão, tal e qual o concebe o ECA, encontra sua origem no art. 11 do texto das Regras Mínimas Uniformes das Nações Unidas para Administração da Justiça de Menores, Regras de Beijing. O conceito remissão constante da tradução para o português foi extraído da versão oficial, em espanhol, daquele documento que define o instrituro como remission.
} 
Por volta dos séculos XVII-XVIII, começam a proliferar as instituições e leis especiais de menores sempre orientados por um caráter assistencial-correcional. Para os órfãos e vagabundos eram previstas as casas de misericórdia e os hospícios, além das prisões para os jovens infratores.

No século XIX, as mudanças produzidas no tratamento do menor se originaram do denominado Child-save movement, que surgiu nos Estados Unidos com a finalidade de tirar as crianças das condições de pobreza em que viviam.

Segundo Coy (1997) foi proposto um direito específico de menores que lhes privou desde o início das garantias jurídicas processuais. Voltado para crianças e jovens com problemas familiares, educativos e econômicos, o child-save movement, no entendimento do autor, foi contra os direitos dos menores.

A Espanha foi receptiva a esta filosofia tutelar, a partir da qual se basearam os códigos que, desde o século passado até anos recentes, formam parte da legislação espanhola referente aos menores. De acordo com essa filosofia, dois são os princípios sobre os quais tradicionalmente se baseiam a determinação da responsabilidade dos menores: a idade e o discernimento.

Assim, o Código Penal de 1822 considera que são inimputáveis os menores de sete anos; os jovens entre sete e doze anos são submetidos a exame de discernimento. O Código de 1848 altera a idade para a inimputabilidade de menores para nove anos. A capacidade de discernir dos jovens situados entre os nove e quinze anos também era submetida à consideração. Aqueles situados entre os quinze e dezoito anos tinham atenuada a responsabilidade em função de seu discernimento.

No final do século XIX e início do século XX, surgiram na Espanha as primeiras leis com o intuito de resguardar e proteger crianças e jovens. A primeira norma com a finalidade específica de proteger as crianças foi a lei de 26 de julho 1878 que proibia o exercício de trabalhos difíceis e perigosos por crianças.

Alguns anos mais tarde, em 1903, foi aprovada a lei sobre mendicância de menores que previa sanções aos pais ou tutores de menores que praticassem a mendicância ${ }^{9}$. A norma recomendava ao Estado o exercício, por meio das administrações, da ação protetora ou tutelar das crianças abandonadas ${ }^{10}$.

Em 1918, foi aprovada a primeira legislação tutelar de menores (inspirada na legislação Belga) e foi criado também o primeiro tribunal tutelar de menores, que começou a funcionar em março de 1920 na cidade de Bilbao.

\footnotetext{
${ }^{9}$ Artigo $5^{\circ}$ da lei: "los agentes de la autoridad deberán detener a los menores de dieciseis años que mendiguem, vaguem o pernocter em parage público, solos o acompañados por personas mayores..."

${ }^{10}$ Artigo $6^{\circ}$ "los niños abandonados y los privados de la asistncia de sus padres por fallecimento de éstos o por impossibilidad absoluta de manterlos...serán sustentados y educados em los Estabelecimientos de Beneficiencia que existan em el município o em província de donde sean naturals”.
} 
Esses tribunais tinham natureza administrativa e sua esfera de competência compreendia tanto as funções de proteção como as de reforma. Com relação à legislação anterior, trouxeram algumas novidades, dentre as quais, podem-se destacar: 1) competência para retirar a criança do convívio de sua respectiva família e entregá-la a outra pessoa ou sociedade tutelar ou ainda interná-la por tempo determinado em um estabelecimento particular ou do Estado; 2) criação da figura do delegado da proteção da infância, encarregado de manter vigilância sobre o menor, a pessoa ou sociedade responsável pela custódia do menor.

Em 1928, a legislação sofre nova alteração quando o código penal aboliu o exame da capacidade de discernir como premissa para a imputabilidade e elevou o limite da idade para o estabelecimento da responsabilidade para dezesseis anos.

Em resposta à alteração do Código Penal, a lei dos tribunais tutelares de 1918 foi alterada em 3 de fevereiro de 1929. A Lei de 1929 manteve a natureza administrativa do tribunal, porém delimitou com maior clareza a faculdade reformadora e protetora de competência dos tribunais.

Entretanto, apesar dessa série de mudanças, é a lei dos tribunais de menores de 1948 (LTTM), originária do pensamento correcional e positivista da época, própria de um modelo tutelar que perdurou até 1992.

A Lei de 1948 representou um momento marcante no processo de consolidação da legislação espanhola. Segundo Sanches ( 2003), ela seguia um modelo de justiça de caráter tutelar ou assistencial que era marcada por considerar a delinquiência condicionada a fatores biológicos, psicológicos ou sociais e que, diante de tal situação, as medidas aplicadas deveriam ter orientação terapêutica, protetora e reformadora.

A Lei em questão não admite o direito de publicidade como garantia dos abusos judiciais (artigo 15). Do mesmo modo, sustenta que não é necessário um advogado defensor nem o Ministério Fiscal, o que, nas palavras de Coy (1997), dá lugar a um processo inquisitivo e sem contraditório.

\section{A legislação do menor após a promulgação da Constituição Espanhola}

Em 1978, depois de quase quarenta anos de ditadura, foi promulgada na Espanha uma Constituição democrática, dando início à transformação do Estado e da ordem jurídica, e introduzindo uma nova concepção acerca dos direitos da infância ${ }^{11}$.

Após a constituição, as leis foram se modificando para se adaptarem à nova ordem jurídica. Assim, em 1985, foi aprovada a Lei Orgânica 6/1985, com a finalidade de garantir o

\footnotetext{
${ }^{11}$ A aprovação da constituição determinou um novo marco jurídico-político de proteção da infância. Esse marco seria essencialmente delimitado pelo reconhecimento do direito fundamental à igualdade (art.14), o dever dos pais de prestar assistência de toda ordem a seus filhos (art.39.3), a obrigação dos poderes públicos de assegurar a proteção da 
direito de tutela judicial a todos os espanhóis sem distinção de idade, o que provocou uma mudança radical na chamada justiça juvenil.

Essa lei, atendendo previsão constitucional, criou os juizados de menores integrados plenamente ao Poder Judiciário, que assumiu as competências dos Tribunais Tutelares de Menores.

Diferentemente dos tribunais de menores, um organismo ao mesmo tempo administrativo e jurisdicional, os juizados de menores constituíam um órgão especializado e plenamente integrado ao Poder Judiciário. Porém, apesar dessas mudanças, a lei de 1948 continuou a regular as atuações e procedimentos dos juizados de menores. Em 1991, provocado pelos juízes de menores, o Tribunal Pleno Constitucional declarou inconstitucional parte da lei dos Tribunais Tutelares de Menores de 1948, (artigo 15²). Em consequência da decisão do Tribunal Pleno Constitucional, foi promulgada a Ley Orgánica 4/1992, reguladora da competência e dos procedimentos dos juizados de menores.

A Ley Orgánica 4/1992 foi concebida em Caráter provisório, como assinalado em sua exposição de motivos e manteve o conteúdo da lei de 1948, com algumas modificações até a entrada em vigor da nova lei penal do menor. Dentre as novidades dessa lei, destacam-se: incorporação de todas as garantias derivadas do ordenamento constitucional; estabelecimento de um processo de natureza sancionadora e educativa; criação de um marco flexível para aplicação das medidas aos menores infratores, considerando como menores aqueles entre a faixa etária de doze a dezesseis anos, com possibilidade de modificação da execução da pena pelos juízes; atribuição ao Ministério Fiscal para investigação e iniciativa processual, com amplas faculdades para decidir sobre a finalização do processo quando considerar que a continuação pode produzir efeitos aflitivos ao menor; e criação de equipes técnicas interdisciplinares encarregadas de informar a situação psicológica, educativa, familiar e social do menor com a finalidade de atingir o objetivo sancionador educativo.

A entrada em vigor do Código Penal de 1995, segundo Sansone e Fiszer(2000) voltou a ser outro momento chave para impulsionar a reforma legislativa, ao fixar em seu Art. 19 a maioridade penal em dezoito anos e exigir uma regulação expressa da responsabilidade dos menores de idade em lei independente.

família e, em particular, a proteção integral aos seus filhos (art. 39.1 e 2) e o reconhecimento às crianças da proteção prevista nos acordos internacionais que velam por seus direitos (art. 39.4) (TESO).

${ }_{12}$ Artigo 15 da LTTM declarado inconstitucional por meio da sentença 36/1991: "las sessiones que los Tribunales Tutelares celebren no serán públicas y el Tribunal no se sujetará a las reglas procesales vigentes en las demás jurisdicciones, limitándose en tramitacion a lo indispensable para puntualizar los hechos en que hayan de fundarse las resoluciones que se dicten, las cuales se redactarán concisamente, haciéndose en ellas mención concreta de las medidas que hubieran de adoptarse. Las decisiones de estos tribunales tomaran el nombre de acuerdos, y la designación del lugar, dia y hora en que habrán de celebrarse las sesiones será hecha por el Presidente del respectivo Tribunal. Los locales en los que actúen los Tribunales de Menores no podrán ser utilizados para actos judiciales. 
Com isso, introduzia-se na Espanha o modelo de responsabilidade que tem como característica básica a junção dos princípios do sistema jurídico à observância da peculiar condição do adolescente como um ser em desenvolvimento.

Assim, nesse contexto histórico, foi aprovada na Espanha a Ley Orgánica 5/2000, reguladora de la responsabilidad penal de los menores (LRPM,) que entrou em vigor em 13 de janeiro de 2001, substituindo completamente a legislação anterior dos Tribunais Tutelares de Menores de 1948.

\section{Ley Orgánica 5/2000, reguladora de la responsabilidad penal de los menores (LORPM)}

Os princípios gerais orientadores da Lei 5/2000 são: natureza formalmente penal, porém, materialmente sancionadora-educativa do procedimento e das medidas aplicáveis aos menores infratores; reconhecimento expresso de todas as garantias constitucionais, considerando o especial interesse ao menor; diferenciação de faixas etárias (14-16/17-18) com diferentes trâmites processuais e sancionadores; flexibilidade na adoção execução das medidas impostas de acordo com as circunstâncias do caso concreto; competência das comunidades autônomas para a execução das medidas impostas na sentença e controle judicial da execução.

A lei reconhece sua natureza de disposição sancionadora, ao exigir dos menores infratores uma verdadeira responsabilidade jurídica, porém coloca como elemento determinante dos procedimentos e das medidas adotadas, a defesa do superior interesse dos menores. Interesse que deve ser valorado com critérios técnicos por equipes de profissionais especializados no âmbito das ciências jurídicas, sem prejuízo da garantia dos princípios legais como o principio acusatório, princípio de defesa e o princípio da presunção da inocência. A lei não esquece o direito da vítima ao estabelecer um procedimento singular, rápido e pouco formalista para o ressarcimento de danos e prejuízos. Visando o interesse e necessidades das vítimas, a lei introduz o princípio da responsabilidade solidária dos pais, tutores ou acolhedores com o menor, responsável pelos atos delituosos. Além disso, há a possibilidade da participação das vítimas, ao oferecer-lhes a oportunidade de intervir nos atos processuais.

A aplicação da lei é de competência de um juiz de menores do lugar onde o menor tenha cometido o ato delituoso. Em caso do cometimento de delitos em diferentes lugares, o órgão judicial competente será aquele do lugar de domicílio do menor. O advogado do menor tem participação em todas as fases do processo, a ele é dado o conhecimento sobre todo o conteúdo do expediente, sendo-lhe facultado propor provas e intervir nos atos que se referem à valoração do interesse do menor e a execução da medida.

\section{7 Âmbito de aplicação}

A Lei 5/2000, em consonância com o ordenamento jurídico espanhol, estabelece a idade para exigir a responsabilidade aos maiores de quatorze anos e menores de dezoito anos. Dispõe 
ainda que poderá ser aplicada aos maiores de dezoito anos e menores de vinte e um anos em casos em que o juiz decidir, ouvidos o Ministério Fiscal, o advogado de defesa e a equipe técnica.

$\mathrm{Na}$ Espanha, não se exige qualquer responsabilidade penal das crianças e jovens abaixo de quatorze anos, por considerar que os atos cometidos por indivíduos nessa faixa etária são, na maioria das vezes, irrelevantes, e, portanto, podem receber resposta educativa no seio da família ou, em alguns casos, podem ser submetidos às normas de proteção previstas no Código Civil e demais disposições vigentes.

\section{Medidas aplicáveis aos menores de idade constantes na LORPM}

Essa lei estabelece um rol de medidas aplicáveis, sob a perspectiva sancionadoraeducativa, primando sempre pelo superior interesse do menor e pela flexibilidade na adoção de medida mais idônea, levando em consideração as características do caso concreto e a evolução pessoal do jovem durante a execução da medida. Essa execução cabe às entidades públicas de proteção e reforma de menores das comunidades autônomas sob o controle do juiz de menores. As medidas constantes da LORPM são: internação em regime aberto, fechado e semiaberto; tratamento terapêutico; assistência a um centro de dia; permanência de fim de semana; liberdade vigiada; convivência com outra pessoa, família ou grupo educativo; prestação de serviços comunitários; realização de tarefas socioeducativas; admoestação.

\section{Modificações a Lei 5/2000}

Mesmo antes de sua entrada em vigor, a Lei 5/2000 (LORPM) foi alterada pela Ley Organica 7/2000, de 22 de dezembro, e pela Lei 9/2000, da mesma data. De acordo com a exposição de motivos da Lei 7/2000, as alterações ocorreram para fazer frente aos crimes de terrorismo e à violência praticada nas ruas por jovens menores de idade pertencentes a grupos armados.

Desde então, a lei vem sofrendo contínuas alterações, mas foi em 2006, com a promulgação da Ley Orgánica 8/2006, que ocorreram as mudanças mais significativas na legislação de menores vigente. Naquele ano, em cumprimento a mandato legal, segundo o qual, após, transcorridos cinco anos da aprovação da Lei 5/2000, o governo realizaria uma avaliação dos resultados da aplicação da lei.

Em uma leitura nas mudanças ocorridas na legislação espanhola, pode-se perceber que, desde a entrada em vigor da Lei 5/2000, o Estado Espanhol vem endurecendo o tratamento 
penal de menores de idade. A justificativa, de acordo com a exposição de motivos ${ }^{13}$ da Lei $8 / 2006$, é o crescente aumento de delitos cometidos por menores, o que tem causado grande preocupação social e contribuído para o desgaste da credibilidade da lei pela sensação de impunidade.

Assim, em resposta a esse aumento da criminalidade entre menores de idade, o Estado impôs medidas mais severas aos menores infratores. Neste sentido, houve um aumento do tempo de internamento em regime fechado, pois, inicialmente, esse tempo não passava de cinco anos e, atualmente, pode chegar a oito anos.

Outra medida de impacto é a possibilidade de o jovem, ao completar dezoito anos durante o período de cumprimento da pena, ser transferido para um centro penitenciário comum. Chama a atenção também no regime espanhol a diferenciação de penas entre as faixas etárias quatorze e quinze anos e de dezesseis e dezessete anos e a flexibilidade com que o juiz pode tomar sua decisão, levando em consideração as peculiaridades de cada caso.

\section{Conclusão}

Como já dito, o modelo de proteção integral adotado pelo Brasil e o modelo de responsabilidade penal adotado pela Espanha respeitam os princípios das normas preconizadas pela Organização das Nações Unidas, do qual os dois países são signatários. As medidas aplicadas aos jovens obedecem a uma perspectiva sancionadora-educativa, considerando sempre o superior interesse do menor.

Uma diferença importante entre o ECA e Lei 4/1992 é que a lei espanhola surgiu no meio jurídico em caráter provisório, como assinalado em sua exposição de motivos, portanto já era certa a substituição por uma nova lei, fato que aconteceu no ano de 2000.

Atualmente, no Brasil, a cada crime hediondo praticado por menores de dezoito anos fica na sociedade um clima de insegurança e a sensação de impunidade. Crescem na mídia as discussões sobre qual a melhor solução para os menores que cometem tais crimes. O estatuto é, muitas vezes, considerado um instrumento de impunidade, já que as penas impostas são consideradas brandas demais.

É cada vez mais frequente o clamor social pela alteração da legislação brasileira de menores. Neste ponto, a Espanha saiu na frente e, em 2006, fez uma reforma geral em sua legislação infanto-juvenil. A sociedade espanhola optou por manter a idade de dezoito anos, porém exigiu do Estado uma resposta mais dura para os crimes praticados por menores.

\footnotetext{
13 Texto constante da exposição de motivos da Lei 8/2006: Las estadísticas revelan un aumento considerable de delitos cometidos por menores, lo que há causado gran preocupacion social y há contribuído a desgastar la credibilidad de la ley por la sensacion de impunidad de las infracciones más cotidianas y frecuentemente cometidas por estos menores, como son los delitos y faltas patrimoniales.
} 
Todos os prazos de cumprimento das penas, em regime aberto ou fechado, foram alterados. As penas aplicadas a jovens de quatorze a quinze anos - que eram de no máximo dois anos - foram alteradas para até cinco anos. Para os jovens de dezesseis a dezoito, as penas máximas passaram de cinco anos para oito anos. Entretanto, a mudança mais polêmica é a possibilidade de o jovem, ao completar dezoito anos, durante o cumprimento da pena, ser transferido para um presídio comum, de acordo com a decisão do juiz.

Atualmente, no Congresso Nacional, tramitam diversas Propostas de Emenda à Constituição (PEC's) que visam diminuir a maioridade penal de dezoito para dezesseis anos. Porém, seria esta uma boa solução para o Brasil? Um jovem de dezesseis anos com sua curiosidade e capacidade de aprendizagem, naturais da idade, colocado junto a presos adultos não se tornaria um verdadeiro discípulo do crime? Não seria necessário, antes de diminuir a idade penal, melhorar o nosso sistema prisional?

Por outro lado, a pena máxima de três anos para crimes hediondos é justa? É correto um jovem reincidente no crime ter sua ficha limpa ao completar dezoito anos? Não resta dúvida de que o ECA representa uma evolução no direito juvenil, pois foi por intermédio dele que as crianças e adolescentes conquistaram o status de sujeito de direito, e isso não pode ser deixado de lado. Porém, o Estatuto não deve ser considerado como um documento inalterável.

Ao acompanhar os debates em torno do assunto, percebe-se que, pelo menos em um ponto, já existe consenso, é o fato de que a legislação da criança e do adolescente precisa de alterações. Por fim, o caminho percorrido pela Espanha seria viável para o Brasil? Ficam esses questionamentos para reflexão.

\section{Referências}

BASTOS, Celso Ribeiro. Curso de Direito Constitucional. 13ed. São Paulo: Saraiva, 1990.

CARVALHO, Francisco Pereira de Bulhões - Direito do Menor. Rio de Janeiro: Ed. Forense, 1977.

COY, Ernesto/Torrente, Ginesa. 1997. Intervención con Infractores: su evolución en España - Anales de psicologia, año/vol. 13, n. 1, p. 39-49 - Universidad de Murcia - Murcia, España..

ESPAÑA. Ley Orgánica 4/1992, de 5 de junio, Reguladora de la Competencia y el Procedimento, 1992

FERREIRA FILHO, Manuel Gonçalves. Comentários à Constituição Brasileira. São Paulo: Saraiva, 1986.

HERINGER JÚNIOR, Bruno. Algumas questões controvertidas do ECA. Disponível em: <www.mp.rs.gov.br/infancia/doutrina/id199.htm>. Acesso em 25 ago 2010.

HERnANZ, Tomás Monteiro. La Política Juvenil en España y El síndrome de Cristóbal Colon. Diário La Lei, n. 6919. Sección Tribuna. 7 abril. 2008. 
MARINHO, Josaphat. Análise da Constituição de 1891. In: O pensamento constitucional brasileiro. Brasília: Câmara dos Deputados, 1978.

MARQUES, Kleyson Anilton Duarte. Redução da Maioridade Penal, Direito Comparado e Realidade Sócio-Política Brasileira. Disponível: 〈Direito.newtonpaiva.org>. Acesso em 10 nov. 2010

MONTEIRO, Luciana de Oliveira. A Judicialização dos conflitos de adolescentes infratores: solução ou mito? Katálysis, v. 9, n. 1, p. 63-74, jan./jun. 2006, Florianópolis SC..

PEREIRA, Rosemary Ferreira de Souza. Algumas Diferenças entre os códigos de menores e o Estatuto da Criança e do Adolescente. Disponível em: <www. fundabrinq.org.br/_Abrinq/documents/peac/diferenças>. Acesso em: 12 ago 2008.

SÁNCHES, Cristina Lopes. La responsabilidad civil derivada del delito o falta cometido por menor de edad mayor de catorce años. 2003. Disponível em: <http:vlex.com/vid/derivada-falta-cometido-edad-catorce-177021>. Acesso em 14 ago 2010.

SANSONE, Virginia/FISZER, Fernando. La Ley Orgánica Reguladora de la responsabilidade de los Menores de España. (Em línea) Disponible en: <www.enj.org> ( Fecha de consulta). Acesso em 14 ago 2010.

SANTOS, Juliana. Redução da Menoridade Penal na Legislação Brasileira e na Influência da Mídia. 2008. Disponível <www.artigosnetsaber.com.br〉. Acesso em 10 jul 2010.

SARAIVA, João Batista Costa. Adolescente em Conflito com a Lei - da indiferença à proteção integral: uma abordagem sobre a responsabilidade penal juvenil. Porto Alegre: Livraria do Advogado, 2003, p. 39.

145-149, set. 2008 .

Não à redução da idade penal. Revista AJURIS, v. 35, n. 111,

SEGALIN, Andréia; TRZCINSKI, Clarete. Ato infracional na adolescência: problematização do acesso ao sistema de justiça. Revista Virtual Texto \& Contexto, v. 5, n. 2, 2006. Disponível em: < http://revistaseletronicas.pucrs.br/ojs/index.php/fass/article/viewFile/1038/817 $>$ Acesso em: 10.jun.2010

SILVA, Carlos Augusto Canedo Gonçalves da. O adolescente infrator e as medidas sócioeducativas: sociedade de consumo, violência urbana e espetáculo midiático. Belo Horizonte: PUC Minas, 2005.

SILVA, Roberto da. A construção do direito à convivência familiar e comunitária no Brasil. Disponível em: <www.ipea.gov.br/Destaques/abrigos/capit.10.pdf.>. Acesso em: 12 ago. 2008.

. Direito do menor X Direito da criança. Disponível em:

<www.neofito.com.br/artigos/art01/civil8>. Acesso em: 22 jun 2010..

SIMÕES, Camila Mattos. Redução da Maioridade Penal e Aplicação de Penas Alternativas. In: www.jurisway.org.br . Acesso em 10 ago.2010.

SOARES, Janine Borges. A construção da responsabilidade penal do adolescente no Brasil: uma breve reflexão histórica. Disponível em: <www.mp.rs.gov.br/infancia/doutrina/id186>. Acesso em: 09 jun 2010.

SOUSA, Sônia Margarida Gomes. História do atendimento à criança e ao adolescente. In: Conferência Nacional dos Direitos da Criança e do Adolescente, IV., 2002, Brasília. Anais ... 
IV conferência Nacional dos Direitos da Criança e do Adolescente. Brasília: Conanda, 2001. p.55.

TESO, Ángeles de palma del. Administraciones Públicas y Protecion de La Infancia - En especial, estúdio de la tutela administrativa de los menores desamparados. INAP - 2006. Disponível em: <http://vlex.com/vid/derivada-falta-cometido-edad-catorce- (177021)〉. Acesso em: 23 jul 2010.

Artigo recebido em: 21/02/2011

Artigo aceito para publicação em: 05/04/2011 